\title{
REVIEW
}

\section{Dopamine-prolactin pathway potentially contributes to the schizophrenia and type 2 diabetes comorbidity}

\author{
C Gragnoli ${ }^{1,2,3}$, GM Reeves ${ }^{4}$, J Reazer ${ }^{5}$ and TT Postolache ${ }^{6,7,8}$
}

\begin{abstract}
Schizophrenia (SCZ) and type 2 diabetes (T2D) are clinically associated, and common knowledge attributes this association to side effects of antipsychotic treatment. However, even drug-naive patients with SCZ are at increased risk for T2D. Dopamine dysfunction has a central role in SCZ. It is well-known that dopamine constitutively inhibits prolactin (PRL) secretion via the dopamine receptor 2 (DR2D). If dopamine is increased or if dopamine receptors hyperfunction, PRL may be reduced. During the first SCZ episode, low PRL levels are associated with worse symptoms. PRL is essential in human and social bonding, as well as it is implicated in glucose homeostasis. Dopamine dysfunction, beyond contributing to SCZ symptoms, may lead to altered appetite and T2D. To our knowledge, there are no studies of the genetics of the SCZ-T2D comorbidity focusing jointly on the dopamine and PRL pathway in the attempt to capture molecular heterogeneity correlated to possible disease manifestation heterogeneity. In this dopamine-PRL pathway-focused-hypothesis-driven review on the association of SCZ with T2D, we report a specific revision of what it is known about PRL and dopamine in relation to what we theorize is one of the missing links between the two disorders. We suggest that new studies are necessary to establish the genetic role of PRL and dopamine pathway in SCZ-T2D comorbidity.
\end{abstract}

Translational Psychiatry (2016) 6, e785; doi:10.1038/tp.2016.50; published online 19 April 2016

\section{INTRODUCTION}

Type 2 diabetes (T2D) is a polygenic complex disorder with a higher incidence of polygenic psychiatric diseases, including schizophrenia (SCZ). ${ }^{1,2}$ Genetic factors of mental complex disorders may be common for some diseases. ${ }^{3-5}$ Even though antidepressants and antipsychotics may cause metabolic dysfunction, some psychiatric disorders increase T2D risk, independently of the therapy. ${ }^{6,7}$ Given that T2D is a leading cause of morbidity and mortality among individuals with SCZ, there is a compelling need to identify mechanisms that increase vulnerability for T2D among individuals with psychotic illness. ${ }^{8}$ In this review, we only focus on a pretreatment SCZ model as an increased risk factor for T2D; we will not discuss the well-known effects of antipsychotics on weight gain or T2D. Of interest, Kirkpatrick et al. ${ }^{9}$ support re-conceptualization of SCZ as a systemic disorder, rather than simply a brain disease. In this paper, we outline evidence to support this theory, as well as highlight genetic research needs to study the dopamine and prolactin (PRL) pathway to investigate possible underlying etiopathogenesis linking psychiatric and metabolic impairment, more specifically the comorbidity of SCZ and T2D. Our hypothesis is that neuroendocrine dysfunction in SCZ confers risk for T2D and that shared risk factors contribute to the clinical SCZ-T2D association.

\section{T2D AND SCZ}

T2D has $8.3 \%$ prevalence worldwide ${ }^{10}$ and causes significant morbidity and mortality. ${ }^{11,12} \mathrm{~T} 2 \mathrm{D}$ onset is usually after 40 years of age, but with increasing incidence at younger ages. ${ }^{13}$
SCZ, a severe chronic illness with $1 \%$ prevalence, is characterized by positive or negative symptoms for a 1-month period, with disturbance signs $\geqslant 6$ months, in addition to continuous social dysfunction. The individual must have at least one of these three positive symptoms: delusions (mostly persecutory); hallucinations (visual or auditory); and disorganized speech; negative symptoms include flat affect and lack of purposeful action. ${ }^{14}$ Disease onset is commonly between ages 15 and $25 .^{15}$

SCZ and T2D are both heterogeneous complex disorders, considered by most to be determined by polygenic causes, thus by several genes with variations of modest effect. Several pathways, including dopaminergic, serotonergic, glutamatergic, cholinergic and GABAergic, have been implicated in SCZ. ${ }^{16,17}$

\section{Evidence of the SCZ-T2D association}

The epidemiology of T2D among individuals with psychotic illness was recently reviewed by Ward and Druss: ${ }^{18}$ T2D prevalence ranges from $1-26 \%$ to $50 \%$ across studies of individuals with psychotic disorders, with median prevalence of 13\%. Clinical evidence of the association of SCZ and T2D derives from several studies. Drug-naive patients with first-episode SCZ have increased prevalence of impaired fasting glucose tolerance and are more insulin resistant with higher glycemia and insulinemia compared with control subjects. ${ }^{19}$ Patients are matched with control subjects for age, gender, lifestyle and anthropometric measures; however, they also have higher cortisol levels than the healthy subjects. ${ }^{19}$ In another study, antipsychotic-naive subjects with non-affective psychosis have a significant increased prevalence of impaired

\footnotetext{
${ }^{1}$ Division of Endocrinology, Diabetes, and Metabolism, Department of Medicine, University of Florida College of Medicine, Jacksonville, FL, USA ; ${ }^{2}$ Department of Public Health Sciences, Penn State College of Medicine, Hershey, PA, USA; ${ }^{3}$ Molecular Biology Laboratory, Bios Biotech Multi-Diagnostic Health Center, Rome, Italy; ${ }^{4}$ Division of Child and Adolescent Psychiatry, Department of Psychiatry, University of Maryland School of Medicine, Baltimore, MD, USA; ${ }^{5}$ Borland Health Sciences Library, University of Florida, Jacksonville, FL, USA; ${ }^{6}$ Rocky Mountain Mental Illness Research Education and Clinical Center, Denver, CO, USA; ${ }^{7}$ Veterans Integrated Service Network 5 MIRECC, Baltimore, MD, USA and ${ }^{8}$ Department of Psychiatry, University of Maryland, Baltimore, MD, USA. Correspondence: Professor C Gragnoli, Division of Endocrinology, Diabetes, and Metabolism, University of Florida College of Medicine, 653-1 West 8th Street, Learning Resource Center, L14, Jacksonville, FL 32209, USA.
} 
glucose tolerance compared with the control group (psychosis group $16 \%$ versus control group $0 \%$ ), which is not due to differences in age, gender, ethnicity, neighborhood of residence, socioeconomic status, body mass index, smoking, aerobic conditioning or cortisolemia. ${ }^{20}$ The study strength is due to the consideration of several potential confounders, including cortisol levels.

Moreover, drug-naive patients with SCZ/schizoaffective disorder, compared with matched healthy subjects, have hepatic insulin resistance (a T2D trait), not attributable to visceral fat mass differences or factors associated with hepatic insulin resistance, indicating a link between SCZ and hepatic insulin resistance. ${ }^{21}$ The study is well conducted as it excludes patients with the following: antipsychotics/any other medication use except for acetaminophen; diabetes; medical/family T2D history; recent history of alcohol abuse or alcohol/cannabis use; alcohol/psychoactive substance abuse dependence disorder; and any somatic illness (for example, metabolic/endocrine diseases, active infection or brain gross structural abnormalities on magnetic resonance imaging). The healthy subjects are matched for age, gender and body mass index. ${ }^{21}$

In addition, glucose metabolites are differentially expressed in peripheral blood mononuclear cells of drug-naive first-episode SCZ subjects versus healthy controls: seven metabolites are significantly increased (glucose, glucose 6-phosphate, fructose, fructose 6-phosphate, glycerate 3-phosphate, succinic acid and ribose 5-phosphate) and four metabolites are significantly decreased (glyceraldehyde-3-phosphate, dihydroxyacetone phosphate, glycerol 3-phosphate and citric acid). ${ }^{22}$ The limitations of this study are the sample size and lack of ethnic diversity. ${ }^{22}$

Of interest, drug-naive SCZ patients and their first-degree relatives have increased prevalence of impaired glucose tolerance compared with healthy controls. ${ }^{23}$ Patients and control subjects are matched for age, gender, ethnicity, smoking and alcohol intake. ${ }^{23}$ Another study show that siblings of SCZ probands have a significantly increased impaired glucose tolerance compared with the control subjects. ${ }^{24}$ The study subjects are matched for age, gender, neighborhood of residence, socio-economic status, body mass index and smoking, but the sample size is small. Newly diagnosed non-affective psychosis and control subjects are interviewed for parental history of $\mathrm{T} 2 \mathrm{D}$, and psychosis is found to be a significant predictor of T2D in either parent. This study is robust as it is performed using a logistic regression model, including multiple potential confounders. The authors conclude that the increased T2D prevalence in the parents of non-affective psychosis subjects may be caused by shared genetic or environmental risk factors, or both. ${ }^{25}$

All above-mentioned studies are not large-scale studies due to the fact the even large specialized medical centers are able to recruit each year only 10-20 patients who are antipsychotic-naive, and free of substance abuse and comorbidities. To summarize, these studies show that drug-naive SCZ patients have impaired glucose levels, insulin action and increased T2D risk.

Clinical studies of PRL, inflammation, cardiovascular mortality and metabolism

A large population-based Study of Health in Pomerania reveals that PRL levels are significantly associated with the inflammatory biomarker interleukin- 6 and white blood cells counts, indicating a possible role of PRL in inflammation. ${ }^{26}$ This is of relevance considering the role of inflammation in T2D. ${ }^{27}$ After adjusting for multiple variables, Haring et al. identify in a very large populationbased Study of Health in Pomerania a significant association of continuous PRL with all-cause mortality and cardiovascular deathspecific mortality in men and women. They find that subjects with the highest PRL tertile have the highest mortality risk compared with subjects with the lowest PRL tertile. ${ }^{28}$ In the same population,
Balbach et al. ${ }^{29}$ show, after multivariable adjustment, an inverse association of low PRL and T2D risk but not of metabolic syndrome risk. Even though the authors use a large sample and longitudinal analyses do not support an association of PRL with metabolic syndrome or T2D, they only test Caucasians and a single non-fasting PRL level, which does not reflect PRL pulsatility. Also, they do not rule out endocrine disorders causing T2D (for example, hyperthyroidism, acromegaly and Cushing syndrome). ${ }^{29}$

\section{SCZ subtypes and glucose metabolism}

SCZ phenotypes are differently associated with T2D: non-deficitSCZ patients (who have more positive symptoms such as hallucinations rather than negative symptoms such as anhedonia) have higher glucose levels than deficit-SCZ patients (who have more negative symptoms rather than positive symptoms), and that the latter have higher glucose levels than the control subjects. Thus, each SCZ phenotype, characterized mostly by persistent positive symptoms versus mainly persistent negative symptoms, may entail a distinct glucose impairment etiology. ${ }^{30}$ As deficit-SCZ patients tend to be less active physically, ${ }^{31}$ their sedentary lifestyle may not explain their reduced, rather than increased, glucose levels compared with the non-deficit-SCZ patients. Interestingly, a study in SCZ subjects shows an association of anhedonia, a feature of deficit-SCZ, with subtle differences in food liking, possibly based on a lower hedonic threshold for food. ${ }^{32}$ Hence, it is very likely that deficit-SCZ subjects tend to eat less as they derive less pleasure from the act of eating. However, other factors will need to explain the lower glucose levels compared with the non-deficitSCZ subjects.

\section{DOPAMINE AND PRL DATA IN SCZ AND T2D}

We believe that there are common gene pathways responsible for the SCZ-T2D association in drug-naive subjects. In particular, we propose that the $P R L$ and dopamine gene pathways may contribute to both $\mathrm{T} 2 \mathrm{D}$ and $\mathrm{SCZ}$, and/or to any metabolic and psychological associated trait predisposing to both diseases.

\section{Dopaminergic and PRL pathway in SCZ}

Our hypothesis stems from the evidence that SCZ etiology is caused in part by the activation of dopamine receptor 2 (DR2D), due to increased dopamine levels and increased DR2D receptor density in the striatum, and by decreased dopaminergic activity in the prefrontal cortex. ${ }^{33}$ Therefore, the activation of DR2D receptors in non-cortical areas and function reduction of dopamine or dopamine receptors in cortical areas contribute to SCZ. Increased dopamine activity is also implicated in impaired reinforcement learning in SCZ. ${ }^{34}$ In addition, research on antipsychotic mechanisms of action has primarily focused on therapeutic effects on dopamine and related systems. ${ }^{35}$

It is important to note that dopamine is the PRL-inhibitory factor, and PRL levels appear to be both decreased in drug-free female patients with SCZ in some studies, ${ }^{36}$ as well as increased in drug-naive patients in other studies, with exclusion of differences attributable to age, gender, smoking, body mass index, ethnicity or socioeconomic status. ${ }^{37}$

PRL levels are higher in females than in males and vary in females across menstrual cycle. Of interest, male and female differences in age of onset, course and prognosis of SCZ suggest possible gender differences in underlying molecular mechanisms of disease pathogenesis. In fact, males have higher SCZ prevalence, earlier age of onset and poorer clinical prognosis. ${ }^{38}$ Gene-sex interactions have been identified for enzymes that catalyze dopamine metabolism. ${ }^{38}$

While Jose et al. ${ }^{39}$ report that PRL levels are higher in drug-free SCZ subjects than in healthy individuals and are significantly associated with severity of psychopathology, suicide risk and 
negative symptoms, other studies suggest possible gender discrepancies on the PRL association with different psychological symptoms. Ramsey et al. $^{40}$ show that PRL level is negatively associated with positive psychosis symptom scores in male drugnaive SCZ subjects; however, the female menstrual cycle is not reported. First-episode drug-naive SCZ male patients have higher levels of PRL compared with control subjects and that the worsening of psychopathologic symptoms presents with PRL level reduction in both females and males. ${ }^{41}$ In a study, morning serum PRL levels are assessed among males who are either (1) drug-naive first-episode psychosis patients, (2) drug-free individuals with SCZ or (3) healthy controls: PRL levels are highest among the drugnaive first-episode patients, and both clinical groups had higher PRL levels compared with the healthy control group. ${ }^{42}$

Of interest, in drug-naive SCZ patients the PRL response to Dfenfluramine, an agent enhancing PRL release, is increased compared with control subjects, closely matched by age, weight, menstrual phase, gender and race. ${ }^{43}$ As fenfluramine increases serotonin, which increases $\mathrm{PRL}$, this finding suggests either possible increased serotonergic tone or increased PRL response to serotonin in drug-naive SCZ patients.

The correlation of higher PRL levels and drug-naive SCZ subjects may be due to PRL receptor (PRLR) resistance, which may lead to reduced PRL action in brain areas important for social and cognitive functions.

We recognize that $P R L$ increases during stress and has a role in social interaction and personal bonding, ${ }^{44}$ as well as in dissociative symptoms of depression. ${ }^{45} \mathrm{PRL}$ is relevant to the mental adequacy to cope with social and personal stress, ${ }^{46}$ a major area of impairment in SCZ. We know that early stressful life events increase the risk of developing $\mathrm{SCZ}_{i}^{47}$ thus, individuals genetically at risk for having inadequate social skills may, if exposed early in life to strong environmental and family stressors, such as parental abuse, develop SCZ. ${ }^{47}$ In a study, elevated PRL level and 'burnout', a measure of psychological stress, are directly associated in males only; however, females are tested in the same phase of menstrual cycle. $^{48}$

\section{Dopaminergic and PRL pathway in T2D}

There is evidence from the literature of dopaminergic pathway and PRL involvement in metabolism. Dopamine synthesis and DR3D receptor activation in pancreatic beta cells regulates insulin secretion and intracellular calcium oscillations, which are related to insulin secretion. ${ }^{49}$ DR2D dopamine receptor-increased activity reduces food intake, ${ }^{50}$ explaining in part why a subject with T2D would benefit from bromocriptine, a dopamine agonist acting on DR2D. ${ }^{51}$ Also, DR2D dopamine receptor-increased activity decreases PRL levels, which in a non-diabetic young subject is associated with insulin resistance, whereas in an older T2D patient it is related to improved insulin sensitivity, ${ }^{52}$ the latter being another possible positive effect of bromocriptine in established T2D. Accordingly, a young individual with a constitutionally increased activity of DR2D and consequential lower PRL levels may be at increased risk for SCZ and T2D. In fact, PRL is essential for pancreatic and beta-cell embryogenesis and ontogenesis, including the perinatal period critical for establishing functional beta-cell reserve and adult insulin secretion capability. Indeed, constitutively decreased PRL levels may impair beta-cell mass growth, ${ }^{53,54}$ thus increasing T2D risk. Further, PRL inhibits beta-cell apoptosis, ${ }^{55,56}$ increases beta-cell survival ${ }^{57}$ and has a role in glucose regulation via glucokinase activity and in insulin secretion. ${ }^{58,59}$ Moreover, PRLR is essential for insulin-producingcell survival ${ }^{60}$ and islets adaptation in pregnancy. ${ }^{61}$ PRL via the PRLR has a role in beta-cell embryogenesis and ontogenesis, glucose homeostasis and beta-cell mass preservation during the insulin-resistant state of pregnancy. ${ }^{62}$
In addition, dopamine elevation and altered dopamine pathway function in SCZ may reduce PRL, thus while impairing glucose homeostasis, ${ }^{58}$ independently alter appetite, ${ }^{63,64}$ induce carbohydrate craving ${ }^{65}$ and contribute to obesity or to T2D onset. ${ }^{66,67}$

\section{Related gene studies in SCZ and T2D}

Association studies focusing only on selected common gene variants of $D R 1 D^{68} D R 2 D,{ }^{69} D R 3 D,^{70} D R 4 D^{71}$ and $D R 5 D,{ }^{72}$ and linkage studies ${ }^{73}$ show inconsistent results in SCZ. One study reports a positive association of $P R L$ gene single-nucleotide polymorphism (SNP) with SCZ. ${ }^{74}$

Studies of DR2D common variants show unclear results in T2D. ${ }^{67,75,76}$ Recent human studies report that the PRL regulatory element (PREB) is associated with eating disorders, ${ }^{77}$ and that a variant near the PRL gene (PRL) is associated with obesity in males. ${ }^{78}$ A PRL gene SNP shows significant associations with lower glycemia during a 2-h oral glucose tolerance tests and a higher level of beta-cell function in a Chinese study. ${ }^{79}$

\section{DOPAMINE AND PRL PATHWAY HYPOTHESIS FOR THE SCZ- T2D COMORBIDITY: NEEDED STUDIES}

It is noteworthy that both low as well as high levels of a hormone may cause a pathological state. Furthermore, the basis for decreased or increased hormonal levels may remain within constitutional hormonal secretion, as well as within hormonal receptor affinity, which both may be determined by genetic variations.

As PRL is either decreased or increased in SCZ drug-naive patients, functional impairment and disease pathogenesis may both depend on reduced as well as increased hormone level or action. Similarly, dopamine pathway alterations may lead to the psychotic symptoms of SCZ.

As in SCZ, ${ }^{36,37}$ T2D can as well be caused by both decreased levels of PRL as well as by PRLR dysfunction leading to increased PRL levels. Higher PRL levels in drug-naive SCZ subjects may be due to PRLR resistance, which may lead to reduced PRL action in brain areas important for social and cognitive functions, as well as to impaired beta-cell insulin secretion and insulin sensitivity, the latter being correlated to increased PRL levels in older adults compared with young adults. ${ }^{52}$

We postulate that some subjects with PRL pathway dysfunction, resulting in either lower PRL levels due to dopamine receptor hyperfunction, or higher PRL levels due to DR2D dysfunction or PRLR resistance, may sustain disrupted mental development (Figure 1).

We hypothesize that the $P R L$ and/or $P R L R$ gene may carry risk variants associated with T2D-correlated metabolic/psychiatric traits, and contribute to SCZ, T2D and/or to their clinical association.

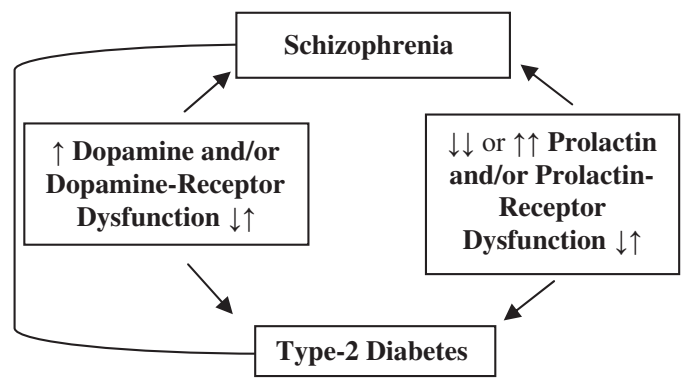

Figure 1. Hypothesized relationship between increased dopamine and/or dopamine receptor dysfunction (increased or decreased affinity), decreased or increased prolactin and/or prolactin-receptor dysfunction (increased or decreased affinity), and resultant schizophrenia and type 2 diabetes. 
Our hypothesis is innovative as, to our knowledge, to date there are no data in the literature regarding genetic screening of whole $P R L$ and PRLR genes in T2D and/or SCZ, except for one PRL SNP association to SCZ. ${ }^{74}$

Dopamine action is mediated by the dopamine receptors DR1D, DR2D, DR3D, DR4D and DR5D. Both increased dopamine function in certain brain areas and decreased dopamine action in others may contribute to SCZ as well as to T2D. Consequently, we postulate that dopamine receptor gene variants may confer risk for the comorbidity of SCZ and T2D, as well as for only SCZ or T2D.

Worth mentioning, the DR1D gene is on 5q35.1, a locus linked to $\mathrm{SCZ}^{80}$ and C-reactive protein in T2D families; ${ }^{81}$ the $D R 2 D$ gene is on $11 \mathrm{q} 23$, a locus linked to both T2D and SCZ. ${ }^{82,83}$ Furthermore, the $P R L$ gene on $6 \mathrm{p} 22.2-21.3$, the $D R 3 D$ gene on $3 q 13.3$, the $D R 4 D$ gene on $11 \mathrm{p} 15.5$ and the $D R 5 D$ gene on $4 \mathrm{p} 16.1$ are located in loci showing common genetic risk inheritance for both T2D and SCZ. The PRLR on 5 p13.2 lies in a locus strongly linked to $\mathrm{SCZ}^{84}$ and nearby the locus linked to C-reactive protein in T2D families. ${ }^{81}$ For all the above-mentioned reasons, we believe that the genes underlying the dopamine and PRL pathways are of high interest to the genetics of SCZ-T2D comorbidity. It would be thus important to screen the PRL, PRLR and dopamine receptor DR1D, DR2D, $D R 3 D, D R 4 D$ and DR5D genes in both T2D and SCZ families and case-control groups.

It would be important to perform linkage and association tests not only in a group of patients with T2D or SCZ but also with associated traits and pre-phenotypes leading to both diseases, as a powerful innovative strategy for gene identification. This suggested method stems from the hypothesis that T2D is a complex disorder potentially characterized by abnormal neuroendocrine and psychological traits, and consequential abnormal behavioral compensatory mechanisms.

These combined neuroendocrine-psychological-behavioral traits may, potentially in the setting of risk susceptibility to slow metabolic activity and beta-cell dysfunction, allow in the long term to develop T2D. Similarly, analogous abnormal mental traits, which if untreated will lead to SCZ, may contribute, in the setting of predisposition to beta-cell failure, to the development of prediabetes and T2D. In addition, we predict that complex gene variants as well as unique gene mutations present in major and minor traits of disease may lead to the onset of the full-complex disorders. ${ }^{85}$ We postulate that the SCZ-T2D association may mask common pathological pathways, and that either the impaired dopamine and/or PRL pathway in SCZ may impair glucose homeostasis, thereby contributing to T2D. However, certain gene variants may explain both $S C Z$ and $T 2 D$, some variants may influence only T2D and others may be unique to SCZ.

Pathway interplay and expected molecular stratification

Despite dopamine pathway's role in SCZ being accepted, it is uncertain to what extent it contributes to disease, and certainly other environmental factors and pathways have a role as well in the disease pathogenesis. ${ }^{86}$ Most likely, SCZ subjects will not all share an identical pathogenesis; heterogeneity of the clinical manifestations will potentially correspond to molecular heterogeneity.

Among the possible SCZ pathways, the serotonergic pathways may have a role in T2D as well. ${ }^{87,88}$ Inhibition of peripheral serotonin synthesis reduces obesity and metabolic dysfunction, ${ }^{87}$ while increased expression of $5-\mathrm{HT}_{2 \mathrm{C}}$ receptors in pancreatic beta cells may inhibit insulin secretion. ${ }^{88}$ The dopaminergic and serotoninergic pathway interact; mutant mice over-expressing DR2D receptors in the striatum, exhibit both decreased willingness to work for reward, as well as upregulation of $5-\mathrm{HT}_{2}$ receptors, which may lead to impaired insulin secretion. ${ }^{89}$

These data anticipate the complex heterogeneity of the molecular genetics underlying the different SCZ subtypes and manifestations. It is unlikely that a single pathway or few genes in a specific pathway will explain either SCZ, or T2D, or their clinical association. Genetic stratification in disease predisposition correlated to phenotype heterogeneity is expected.

As not all SCZ patients develop T2D, and only some T2D subjects will present psychological traits overlapping with presymptoms of SCZ, we hypothesize that a subgroup of individuals comorbid for both SCZ and T2D may have inherited genetically impaired dopamine and PRL pathways. It would be necessary to stratify the genetic risk in these pathways, and correlate it with sub-phenotypes of SCZ and T2D. The correlation of the genes and their variations with the phenotype(s), or the lack of thereof, may further elucidate the genetic basis of the SCZ-T2D association.

\section{Possible impact}

Our proposed theory challenges the currently accepted paradigm that T2D is only a metabolic disorder, and that SCZ is merely a mental disorder, which affects few unlucky individuals carrying unfavorable gene variants. Our hypothesis may produce a shift in the attention given to subjects with T2D-familial risk in terms of psychological traits contributing to disease. In subjects with family history for SCZ, our hypothesis may contribute to major awareness toward the metabolic phenotypes of pre-diabetes. Thus, the creation of a new way to think about the mental alterations in SCZ and the metabolic dysfunction of T2D will open a new horizon of approaches, experimental designs and, in the long term, possibly cognitive-behavioral and preventive therapies for at-risk subjects. In fact, individuals with SCZ often have a gradual period of decline over 1-2 years before development of overt psychosis, referred to as 'prodromal' or 'ultrahigh-risk state', ${ }^{90}$ so there is a window of opportunity for early therapeutic interventions. If our theory is proven valid via genetic studies determining the gene variants in the dopamine-PRL pathway predisposing to SCZ and consequently to T2D, screening for disease biomarkers, such as PRL levels, or for gene risk-variant carriers could be performed in children and teenagers with increased SCZ-familial risk or presenting with cognitive, developmental, emotional and/or behavioral issues, resembling possible predisposition to SCZ. Finally, if these young subjects were confirmed to carry a genetic risk variant for SCZ, they could be evaluated and monitored more closely regarding their mental and cognitive well-being in their common environment, and stress factors prevention and reduction at school, in the family and in the peer setting could be implemented. Similarly, targeted nutrition and exercise programs, as well as mind-body calming biofeedback techniques could be realized. To prove our idea, different patient sub-phenotypes per disorder would be required to identify a potential common neuro-endocrine-mental-metabolic dysfunction. By proving that gene variants responsible for one disorder are contributing to the other disorder, or to any of its associated traits, the foundation of the genetic overlap between the two diseases could be built, as well as of the existence of new distinct genetically combined metabolic and mental-behavioral traits.

\section{BEYOND OUR HYPOTHESIS}

Pleiotropic theory, causality theory, disease model

We believe in the hypothesis of the existence of some risk genes with independent pleiotropic effects, consequently causing both T2D and SCZ. One example may be represented by the PSMD9 gene, which we show as strongly linked to $T 2 D^{91}$ and others report as one of the major gene players in SCZ. ${ }^{92}$ PSMD9 is a co-activator and interacting partner of several proteins, thus it may well have pleiotropic effects on different pathways, as well as mediate inflammation. ${ }^{93}$ 
However, we consider the causality hypothesis as having stronger impact on the SCZ-T2D comorbidity. In fact, an impaired pathway in early-onset SCZ may determine T2D over time.

Of note, some patients with both diseases may have genes involved independently in each disease as well, and not sharing the common pathway of SCZ-T2D or only partially responsible for it.

We also need to consider that the SCZ-T2D comorbidity may be due (1) an oligogenic disease model for some families with mildly deleterious mutations in few genes, as well as (2) a monogenic or digenic disease model for other families with frankly deleterious mutations in one or two genes, respectively, and finally (3) a polygenic disease model where the contribution of several genes with modestly deleterious mutations is needed for the diseases to manifest.

Other candidate genes for SCZ-T2D comorbidity

There are several candidate genes for SCZ-T2D comorbidity and they mostly derive from the overlapping data in the T2D and SCZ genome-wide association studies. ${ }^{8}$ We hereby report some of the identified candidate genes for both SCZ and T2D, and describe our view on their potential limitations for the SCZ-T2D comorbidity, especially for a possible monogenic, digenic or oligogenic disease model, in which candidate genes specifically affecting SCZ and T2D common pathways are needed to establish comorbidity.

Superoxide dismutase 2 (SOD2) is associated with diabetic complications ${ }^{94}$ and $T 2 D^{95}$ but not all studies confirm an association with T2D. ${ }^{96}$ No data confirm an association with SCZ. Glutathione-S-transferase M1 (GSM1) is associated with $\mathrm{T}^{2} \mathrm{D}^{97}$ and SCZ. ${ }^{98}$ As oxidative stress is present in aging disorders of the general population at a higher prevalence than the SCZ-T2D association, we do not think that oxidative stress is the cause of SCZ-T2D comorbidity, but that a GSM1 or SOD2 variation may predispose to inability to counter-effect oxidative stress triggered by other factors. Apolipoprotein $\mathrm{D}(A P O D)$ is associated to $T 2 \mathrm{D}^{99}$ but its implicated role in SCZ is not confirmed in all studies. ${ }^{100}$ Wolfram syndrome 1 (WFS1) confers risk to T2D, ${ }^{101}$ and, despite high mental disorder prevalence (but not SCZ) in patients with Wolfram syndrome, WFS1 role in SCZ is not supported. ${ }^{102,103}$

Despite impairment of epidermal growth factor (EGF) in SCZautoptic brains ${ }^{104}$ and islet cells of T2D patients, ${ }^{105}$ EGF association studies with SCZ are inconsistent, ${ }^{106,107}$ and to our knowledge, there are currently no genetic studies of EGF in T2D.

Tumor necrosis factor (TNF) is a cytokine with effects on insulin resistance, but data showing a genetic role for TNF in T2D are inconsistent. ${ }^{108,109}$ TNF contribution is reported in SCZ. ${ }^{110}$ Data show that interleukin- 6 and interleukin-1 beta may contribute to the SCZ-T2D link. ${ }^{8}$ Even though inflammatory molecules such as TNF, interleukin- 6 and interleukin- 1 beta may contribute to both disease pathogenesis, and inherited gene variants of these inflammatory molecules may predispose to increased inflammation, the inflammation-driven pathogenic role is likely not the prior one contributing to SCZ-T2D comorbidity, as inflammation is present in aging disorders at a higher prevalence than the SCZ-T2D association.

Methylenetetrahydrofolate reductase contributes to homocysteine metabolism and hyperhomocysteinemia is associated with $T 2 D^{111}$ and $S C Z,{ }^{112}$ but it may represent a disorder epiphenomenon.

The strongest T2D-risk gene, TCF7L2, is associated with SCZ in few studies; $i^{113,114}$ however, TCF7L2 odds ratio for both diseases does not explain the genetic predisposition risk (T2D $\lambda_{s} \approx 3$ and SCZ $\left.\lambda_{\mathrm{s}} \approx 2\right)$.

Of note, studies have failed to replicate findings of other common SNPs significantly associated with T2D and psychotic disorders. ${ }^{115}$ However, the variable allele frequencies and linkage disequilibrium blocks among different ethnic groups and the sample sizes used are limitations of these studies. Most importantly, the SNPs significantly associated in genome-wide association studies may only be a marker of the causative disorders variants, thus explaining the difficulty in replication.

There is no consensus on androgen receptor's $(A R)$ role in SCZ; ${ }^{116-118} A R$ variants are associated with obesity in T2D men, ${ }^{119}$ and androgens may be implicated in beta-cell dysfunction. ${ }^{120}$ Thus, $A R$ gene may confer risk for both $\mathrm{T} 2 \mathrm{D}$ and $\mathrm{SCZ}$, and its role in SCZ-T2D comorbidity cannot be ruled out.

Neuropeptide $\mathrm{Y}$ (NPY) gene is associated with $\mathrm{T}_{2} \mathrm{D}^{121}$ and $\mathrm{SCZ}{ }^{122}$ but less consistently with SCZ. ${ }^{123}$ NPY is of interest to the hypothesized correlation of the dopamine-PRL pathway with the SCZ-T2D comorbidity, as NPY appears, beyond stimulating appetite, to amplify the inhibitory action of dopamine on PRL secretion. ${ }^{124}$ Thus, an altered NPY pathway may have effects on the dopamine-PRL pathway. It is our understanding that the NPY pathway represents, together with the serotonergic pathway, another possible player in the SCZ-T2D association.

\section{Epigenetics, SCZ and T2D}

There is evidence that epigenetic pathways interacting with genetic and environmental factors have a role in the pathogenesis of T2D and SCZ. Early-life environmental factors, gestational and birth abnormalities (for example, low birth weight) and epigenetic programming emerge as risk factors for $\mathrm{T}_{2} \mathrm{D}^{125}$ and SCZ/psychotic disorders, ${ }^{126}$ indicating that phenomena of adaptation may contribute to these diseases. Early growth and prenatal abnormalities predict in the long term-via epigenetic pathways-an increased risk for T2D. ${ }^{127}$ One of many examples of possible interplay between genetics and epigenetics in diabetes is given by the maturity-onset diabetes of the young 4 (MODY4) IPF-1 gene, an essential transcription factor in pancreas development and proliferation. While the MODY4 IPF-1 P33T variant contributes to monogenic diabetes, gestational diabetes, low birth weight, miscarriages and early postnatal death, ${ }^{128}$ fetal undernutrition silences the transcription of Pdx1 (rat homologous of MODY4 IPF-1) via promoter DNA methylation and histone modifications. ${ }^{129}$

In addition, below-average-sized babies carry a significantly higher risk for SCZ spectrum disorders. ${ }^{130}$ Hormones affect adult metabolism and epigenetic programming, ${ }^{131}$ which may affect dopamine, NMDA and GABA gene function contributing to SCZ. ${ }^{132}$ Moreover, $D R D 3$ gene hypermethylation is significantly associated with SCZ risk. ${ }^{133}$ Of great interest, DNA methylation of the DRD2 regulatory region is described in monozygotic twin pairs, one concordant and one discordant for SCZ; the affected twin from the pair discordant for SCZ is epigenetically closer to the affected concordant twins than to his unaffected monozygotic co-twin. ${ }^{134}$ In drug-naive SCZ patients, serotonin transporter (5-HTT)-reduced expression is correlated with 5-HTT promoter DNA hypermethylation, indicating that $5-H T T$ epigenetic hypo-activity is linked to SCZ. ${ }^{135}$ The same author also reports epigenetic alterations of the dopaminergic system in SCZ and bipolar disorder. ${ }^{136}$ In SCZ, the soluble catechol-O-methyltransferase (S-COMT) gene is identified as significantly hypermethylated as well as a dysregulated epigenome, the latter more pronounced in early-onset patients. ${ }^{137}$ There are currently no studies of PRL pathway epigenetics in T2D or SCZ.

\section{CONCLUSION}

We strongly advocate new research in the area of associated mental and metabolic disorders to create a new focus on the neuroendocrine-mental-metabolic dysfunctions, which may characterize pre-disease states, and develop novel prevention strategies that address both conditions. If we open our eyes to the idea of this joint pathogenesis of, at first sight, so different 
disorders, we might be able to advance research in early prevention and treatment for both conditions.

In summary, there is a scientific need for the development of a new focus on the genetic predisposition to shared mental and metabolic dysfunctions, gender-related different genetic susceptibility, epigenetic mechanisms and their long-term effects on mental illness and T2D. As a result, new genetic research, experimental studies and longitudinal investigations are now needed. In the long term, clinical trials might be started: new therapies such as nutritional preventions (for example, diet with controlled or reduced tyrosine intake) may prevent or counteract dopamine pathway impairment in subjects at risk for increased dopamine levels or dopamine receptor function before both their first-episode psychosis onset and T2D. In addition, later on, early environmental and pharmacological interventions may reduce the prevalence of both SCZ and T2D. Furthermore, therapies with PRL agonists acting on the beta cell, insulin action and brain may reduce $\mathrm{T} 2 \mathrm{D}$ risk and SCZ-related symptoms. We do expect that within SCZ and T2D there might be a subgroup of patients with genetic, epigenetic and functional impairment of the dopaminePRL pathway, and that this line of investigation will potentially lead to the application of precision medicine principles to T2D and SCZ, potentially even before the first episode of the psychotic disorder, and perhaps even before its prodrome became clinically apparent.

\section{CONFLICT OF INTEREST}

The authors declare no conflict of interest.

\section{REFERENCES}

1 Medved V, Jovanovic N, Knapic VP. The comorbidity of diabetes mellitus and psychiatric disorders. Psychiatr Danub 2009; 21: 585-588.

2 Newcomer JW. Metabolic syndrome and mental illness. Am J Manag Care 2007; 13(7 Suppl): S170-S177.

3 Gottesman II. Schizophrenia Genesis: The Origins of Madness. W H Freeman: New York, NY, USA, 1991.

4 Grozeva D, Kirov G, Ivanov D, Jones IR, Jones L, Green EK et al. Rare copy number variants: a point of rarity in genetic risk for bipolar disorder and schizophrenia. Arch Gen Psychiatry 2010; 67: 318-327.

5 Williams HJ, Norton N, Dwyer S, Moskvina V, Nikolov I, Carroll L et al. Fine mapping of ZNF804A and genome-wide significant evidence for its involvement in schizophrenia and bipolar disorder. Mol Psychiatry 2011; 16: 429-441.

6 Bushe C, Holt R. Prevalence of diabetes and impaired glucose tolerance in patients with schizophrenia. Br J Psychiatry Suppl 2004; 47: S67-S71.

7 Gragnoli C. Hypothesis of the neuroendocrine cortisol pathway gene role in the comorbidity of depression, type 2 diabetes, and metabolic syndrome. Appl Clin Genet 2014; 7: 43-53.

8 Lin PI, Shuldiner AR. Rethinking the genetic basis for comorbidity of schizophrenia and type 2 diabetes. Schizophr Res 2010; 123: 234-243.

9 Kirkpatrick B, Miller B, Garcia-Rizo C, Fernandez-Egea E. Schizophrenia: a systemic disorder. Clin Schizophr Relat Psychoses 2014; 8: 73-79.

10 Federation ID IDF Diabetes Atlas. 6th edn. IDF: Brussels, Belgium.

11 Fox CS, Coady S, Sorlie PD, D'Agostino RB Sr, Pencina MJ, Vasan RS et al. Increasing cardiovascular disease burden due to diabetes mellitus: the Framingham Heart Study. Circulation 2007; 115: 1544-1550.

12 Preis SR, Hwang SJ, Coady S, Pencina MJ, D'Agostino RB Sr, Savage PJ et al. Trends in all-cause and cardiovascular disease mortality among women and men with and without diabetes mellitus in the Framingham Heart Study, 1950 to 2005. Circulation 2009; 119: 1728-1735.

13 Pulgaron ER, Delamater AM. Obesity and type 2 diabetes in children: epidemiology and treatment. Curr Diab Rep 2014; 14: 508.

14 Jufe GS. [Schizophrenia according to DSM-5]. Vertex 2014; 25: 36-42.

15 Hafner H, Maurer K, Loffler W, Riecher-Rossler A. The influence of age and sex on the onset and early course of schizophrenia. Br J Psychiatry 1993; 162: 80-86.

16 Javitt DC. Glutamate and schizophrenia: phencyclidine, N-methyl-D-aspartate receptors, and dopamine-glutamate interactions. Int Rev Neurobiol 2007; 78: 69-108.

17 Dean B. A predicted cortical serotonergic/cholinergic/GABAergic interface as a site of pathology in schizophrenia. Clin Exp Pharmacol Physiol 2001; 28: 74-78.
18 Ward M, Druss B. The epidemiology of diabetes in psychotic disorders. Lancet Psychiatry 2015; 2: 431-451.

19 Ryan MC, Collins P, Thakore JH. Impaired fasting glucose tolerance in first-episode, drug-naive patients with schizophrenia. Am J Psychiatry 2003; 160: 284-289.

20 Fernandez-Egea E, Bernardo M, Donner T, Conget I, Parellada E, Justicia A et al. Metabolic profile of antipsychotic-naive individuals with non-affective psychosis. Br J Psychiatry 2009; 194: 434-438.

21 van Nimwegen $\sqcup$, Storosum JG, Blumer RM, Allick G, Venema HW, de Haan L et al. Hepatic insulin resistance in antipsychotic naive schizophrenic patients: stable isotope studies of glucose metabolism. J Clin Endocrinol Metab 2008; 93: 572-577.

22 Liu ML, Zhang XT, Du XY, Fang Z, Liu Z, Xu Y et al. Severe disturbance of glucose metabolism in peripheral blood mononuclear cells of schizophrenia patients: a targeted metabolomic study. J Transl Med 2015; 13: 226.

23 Spelman LM, Walsh PI, Sharifi N, Collins P, Thakore JH. Impaired glucose tolerance in first-episode drug-naive patients with schizophrenia. Diabet Med 2007; 24: 481-485.

24 Fernandez-Egea E, Bernardo M, Parellada E, Justicia A, Garcia-Rizo C, Esmatjes E et al. Glucose abnormalities in the siblings of people with schizophrenia. Schizophr Res 2008; 103: 110-113.

25 Fernandez-Egea E, Miller B, Bernardo M, Donner T, Kirkpatrick B. Parental history of type 2 diabetes in patients with nonaffective psychosis. Schizophr Res 2008; 98: 302-306.

26 Friedrich N, Schneider HJ, Spielhagen C, Markus MR, Haring R, Grabe HJ. The association of serum prolactin concentration with inflammatory biomarkerscross-sectional findings from the population-based Study of Health in Pomerania. Clin Endocrinol (Oxf) 2011; 75: 561-566.

27 Kohlgruber A, Lynch L. Adipose tissue inflammation in the pathogenesis of type 2 diabetes. Curr Diab Rep 2015; 15: 92.

28 Haring R, Friedrich N, Volzke H, Vasan RS, Felix SB, Dorr M et al. Positive association of serum prolactin concentrations with all-cause and cardiovascular mortality. Eur Heart J 2014; 35: 1215-1221.

29 Balbach L, Wallaschofski H, Volzke H, Nauck M, Dorr M, Haring R. Serum prolactin concentrations as risk factor of metabolic syndrome or type 2 diabetes? BMC Endocr Disord 2013; 13: 12.

30 Kirkpatrick B, Fernandez-Egea E, Garcia-Rizo C, Bernardo M. Differences in glucose tolerance between deficit and nondeficit schizophrenia. Schizophr Res 2009; 107: 122-127.

31 Vancampfort D, De Hert M, Stubbs B, Ward PB, Rosenbaum S, Soundy A et al. Negative symptoms are associated with lower autonomous motivation towards physical activity in people with schizophrenia. Compr Psychiatry 2015; 56: 128-132.

32 Folley BS, Park S. Relative food preference and hedonic judgments in schizophrenia. Psychiatry Res 2010; 175: 33-37.

33 Howes OD, Kapur S. The dopamine hypothesis of schizophrenia: version III-the final common pathway. Schizophr Bull 2009; 35: 549-562.

34 Deserno L, Boehme R, Heinz A, Schlagenhauf F. Reinforcement learning and dopamine in schizophrenia: dimensions of symptoms or specific features of a disease group? Front Psychiatry 2013; 4: 172.

35 Brisch R, Saniotis A, Wolf R, Bielau H, Bernstein HG, Steiner J et al. The role of dopamine in schizophrenia from a neurobiological and evolutionary perspective: old fashioned, but still in vogue. Front Psychiatry 2014; 5: 47.

36 Rao ML, Gross G, Strebel B, Halaris A, Huber G, Braunig P et al. Circadian rhythm of tryptophan, serotonin, melatonin, and pituitary hormones in schizophrenia. Biol Psychiatry 1994; 35: 151-163.

37 Garcia-Rizo C, Fernandez-Egea E, Oliveira C, Justicia A, Parellada E, Bernardo M et al. Prolactin concentrations in newly diagnosed, antipsychotic-naive patients with nonaffective psychosis. Schizophr Res 2012; 134: 16-19.

38 Godar SC, Bortolato M. Gene-sex interactions in schizophrenia: focus on dopamine neurotransmission. Front Behav Neurosci 2014; 8: 71.

39 Jose J, Nandeesha H, Kattimani S, Meiyappan K, Sarkar S, Sivasankar D. Association between prolactin and thyroid hormones with severity of psychopathology and suicide risk in drug free male schizophrenia. Clin Chim Acta 2015; 444C: $78-80$.

40 Ramsey JM, Schwarz E, Guest PC, van Beveren NJ, Leweke FM, Rothermundt M et al. Distinct molecular phenotypes in male and female schizophrenia patients. PloS One 2013; 8: e78729.

41 Gorobets LN, Matrosova MI. [Specialties of prolactin secretion and peripheral reproductive sex hormones in patients with of first episode of schizophrenia]. $Z \mathrm{~h}$ Nevrol Psikhiatr Im S S Korsakova 2010; 110: 17-22.

42 Albayrak Y, Beyazyuz M, Beyazyuz E, Kuloglu M. Increased serum prolactin levels in drug-naive first-episode male patients with schizophrenia. Nord J Psychiatry 2014; 68: 341-346.

43 Abel KM, O'Keane V, Murray RM. Enhancement of the prolactin response to d-fenfluramine in drug-naive schizophrenic patients. Br J Psychiatry 1996; 168: 57-60. 
44 Gordon I, Zagoory-Sharon O, Leckman JF, Feldman R. Prolactin, oxytocin, and the development of paternal behavior across the first six months of fatherhood. Horm Behav 2010; 58: 513-518.

45 Bob P, Fedor-Freybergh P, Jasova D, Bizik G, Susta M, Pavlat J et al. Dissociative symptoms and neuroendocrine dysregulation in depression. Med Sci Monit 2008; 14: CR499-CR504.

46 Neumann ID. The advantage of social living: brain neuropeptides mediate the beneficial consequences of sex and motherhood. Front Neuroendocrinol 2009; 30: 483-496.

47 Rubino IA, Nanni RC, Pozzi DM, Siracusano A. Early adverse experiences in schizophrenia and unipolar depression. J Nerv Ment Dis 2009; 197: 65-68.

48 Lennartsson AK, Billig $\mathrm{H}$, Jonsdottir $\mathrm{IH}$. Burnout is associated with elevated prolactin levels in men but not in women. J Psychosom Res 2014; 76: 380-383.

49 Ustione A, Piston DW. Dopamine synthesis and D3 receptor activation in pancreatic beta-cells regulates insulin secretion and intracellular $[\mathrm{Ca}(2+)]$ oscillations. Mol Endocrinol 2012; 26: 1928-1940.

50 Anderberg $\mathrm{RH}$, Anefors $\mathrm{C}$, Bergquist F, Nissbrandt H, Skibicka KP. Dopamine signaling in the amygdala, increased by food ingestion and GLP-1, regulates feeding behavior. Physiol Behav 2014; 136: 135-144.

51 Garber AJ, Blonde L, Bloomgarden ZT, Handelsman Y, Dagogo-Jack S. The role of bromocriptine-QR in the management of type 2 diabetes expert panel recommendations. Endocr Pract 2013; 19: 100-106.

52 Wagner R, Heni M, Linder K, Ketterer C, Peter A, Bohm A et al. Age-dependent association of serum prolactin with glycaemia and insulin sensitivity in humans. Acta Diabetol 2014; 51: 71-78.

53 Huang Y, Chang Y. Regulation of pancreatic islet beta-cell mass by growth factor and hormone signaling. Prog Mol Biol Transl Sci 2014; 121: 321-349.

54 Auffret J, Freemark M, Carre N, Mathieu Y, Tourrel-Cuzin C, Lombes $M$ et al. Defective prolactin signaling impairs pancreatic beta-cell development during the perinatal period. Am J Physiol Endocrinol Metab 2013; 305: E1309-E1318.

55 Terra LF, Garay-Malpartida MH, Wailemann RA, Sogayar MC, Labriola L. Recombinant human prolactin promotes human beta cell survival via inhibition of extrinsic and intrinsic apoptosis pathways. Diabetologia 2011; 54: 1388-1397.

56 Yamamoto T, Mita A, Ricordi C, Messinger S, Miki A, Sakuma Y et al. Prolactin supplementation to culture medium improves beta-cell survival. Transplantation 2010; 89: 1328-1335.

57 Yamamoto T, Ricordi C, Mita A, Miki A, Sakuma Y, Molano RD et al. beta-Cell specific cytoprotection by prolactin on human islets. Transplant Proc 2008; 40: 382-383.

58 Sorenson RL, Johnson MG, Parsons JA, Sheridan JD. Decreased glucose stimulation threshold, enhanced insulin secretion, and increased beta cell coupling in islets of prolactin-treated rats. Pancreas 1987; 2: 283-288.

59 Weinhaus AJ, Stout LE, Bhagroo NV, Brelje TC, Sorenson RL. Regulation of glucokinase in pancreatic islets by prolactin: a mechanism for increasing glucosestimulated insulin secretion during pregnancy. J Endocrinol 2007; 193: 367-381.

60 Arumugam R, Fleenor D, Freemark M. Knockdown of prolactin receptors in a pancreatic beta cell line: effects on DNA synthesis, apoptosis, and gene expression. Endocrine 2014; 46: 568-576.

61 Sorenson RL, Brelje TC. Prolactin receptors are critical to the adaptation of islets to pregnancy. Endocrinology 2009; 150: 1566-1569.

62 Huang C, Snider F, Cross JC. Prolactin receptor is required for normal glucose homeostasis and modulation of beta-cell mass during pregnancy. Endocrinology 2009; 150: 1618-1626.

63 Axel AM, Mikkelsen JD, Hansen HH. Tesofensine, a novel triple monoamine reuptake inhibitor, induces appetite suppression by indirect stimulation of alpha (1) adrenoceptor and dopamine $D(1)$ receptor pathways in the diet-induced obese rat. Neuropsychopharmacology 2010; 35: 1464-1476.

64 Volkow ND, Wang GJ, Telang F, Fowler JS, Thanos PK, Logan J et al. Low dopamine striatal D2 receptors are associated with prefrontal metabolism in obese subjects: possible contributing factors. Neuroimage 2008; 42: 1537-1543.

65 Berridge KC, Ho CY, Richard JM, Difeliceantonio AG. The tempted brain eats: Pleasure and desire circuits in obesity and eating disorders. Brain Res 1350: 43-64.

66 Levitan RD, Masellis M, Lam RW, Muglia P, Basile VS, Jain U et al. Childhood inattention and dysphoria and adult obesity associated with the dopamine D4 receptor gene in overeating women with seasonal affective disorder. Neuropsychopharmacology 2004; 29: 179-186.

67 Barnard ND, Noble EP, Ritchie T, Cohen J, Jenkins DJ, Turner-McGrievy G et al. D2 dopamine receptor Taq1A polymorphism, body weight, and dietary intake in type 2 diabetes. Nutrition 2009; 25: 58-65.

68 Zhang C, Fang Y, Xie B, Cheng W, Du Y, Wang D et al. No genetic association between dopamine D1 receptor gene and [early onset] schizophrenia. Psychiatry Res 177: 350-353.

69 Pakhomova SA, Korovaitseva Gl, Monchakovskaia M, Vil'ianov VB, Frolova LP, Kasparov SV et al. [Molecular-genetic study of early-onset schizophrenia]. Zh Nevrolog Psikhiatr Im S S Korsakova 2010; 110: 66-69.
70 Nunokawa A, Watanabe Y, Kaneko N, Sugai T, Yazaki S, Arinami T et al. The dopamine D3 receptor (DRD3) gene and risk of schizophrenia: case-control studies and an updated meta-analysis. Schizophr Res 2010; 116: 61-67.

71 Lung FW, Shu BC, Kao WT, Chen CN, Ku YC, Tzeng DS. Association of DRD4 UVNTR and TP53 codon 72 polymorphisms with schizophrenia: a casecontrol study. BMC Med Genet 2009; 10: 147.

72 Muir WJ, Thomson ML, McKeon P, Mynett-Johnson L, Whitton C, Evans KL et al. Markers close to the dopamine D5 receptor gene (DRD5) show significant association with schizophrenia but not bipolar disorder. Am J Med Genet 2001; 105: 152-158.

73 Kalsi G, Sherrington R, Mankoo BS, Brynjolfsson J, Sigmundsson T, Curtis D et al. Linkage study of the D5 dopamine receptor gene (DRD5) in multiplex Icelandic and English schizophrenia pedigrees. Am J Psychiatry 1996; 153: 107-109.

74 Rybakowski JK, Dmitrzak-Weglarz M, Kapelski P, Hauser J. Functional -1149 g/t polymorphism of the prolactin gene in schizophrenia. Neuropsychobiology 2012; 65: 41-44.

75 Guigas B, de Leeuw van Weenen JE, van Leeuwen N, Simonis-Bik AM, van Haeften TW, Nijpels $G$ et al. Sex-specific effects of naturally occurring variants in the dopamine receptor D2 locus on insulin secretion and type 2 diabetes susceptibility. Diabet Med 2014; 31: 1001-1008.

76 Jenkinson CP, Hanson R, Cray K, Wiedrich C, Knowler WC, Bogardus C et al. Association of dopamine D2 receptor polymorphisms Ser311Cys and TaqIA with obesity or type 2 diabetes mellitus in Pima Indians. Int J Obes Relat Metab Disord 2000; 24: 1233-1238.

77 Gratacos M, Costas J, de Cid R, Bayes M, Gonzalez JR, Baca-Garcia E et al. Identification of new putative susceptibility genes for several psychiatric disorders by association analysis of regulatory and non-synonymous SNPs of 306 genes involved in neurotransmission and neurodevelopment. Am J Med Genet B Neuropsychiatr Genet 2009; 150B: 808-816.

78 Nilsson L, Olsson AH, Isomaa B, Groop L, Billig H, Ling C. A common variant near the PRL gene is associated with increased adiposity in males. Mol Genet Metab 2011; 102: 78-81.

79 Kong X, Zhang X, Zhao Q, He J, Chen L, Zhao Z et al. Obesity-related genomic loci are associated with type 2 diabetes in a Han Chinese population. PloS One 2014; 9: e104486.

80 Escamilla MA, Ontiveros A, Nicolini H, Raventos H, Mendoza R, Medina R et al. A genome-wide scan for schizophrenia and psychosis susceptibility loci in families of Mexican and Central American ancestry. Am J Med Genet B Neuropsychiatr Genet 2007; 144B: 193-199.

81 Keenan HA, Poznik GD, Varo N, Schneider J, Almasy L, Warram JH et al. Identification of a locus modulating serum C-reactive protein levels on chromosome 5p15. Atherosclerosis 2008; 196: 863-870.

82 Baier L, Kovacs P, Wiedrich C, Cray K, Schemidt A, Shen GQ et al. Positional cloning of an obesity/diabetes susceptibility gene(s) on chromosome 11 in Pima Indians. Ann N Y Acad Sci 2002; 967: 258-264.

83 Bulayeva KB, Glatt SJ, Bulayev OA, Pavlova TA, Tsuang MT. Genome-wide linkage scan of schizophrenia: a cross-isolate study. Genomics 2007; 89: 167-177.

84 Bespalova IN, Angelo GW, Durner M, Smith CJ, Siever LJ, Buxbaum JD et al. Fine mapping of the $5 \mathrm{p} 13$ locus linked to schizophrenia and schizotypal personality disorder in a Puerto Rican family. Psychiatr Genet 2005; 15: 205-210.

85 Dickson SP, Wang K, Krantz I, Hakonarson H, Goldstein DB. Rare variants create synthetic genome-wide associations. PLoS Biol 8: e1000294.

86 Lau Cl, Wang HC, Hsu JL, Liu ME. Does the dopamine hypothesis explain schizophrenia? Rev Neurosci 2013; 24: 389-400.

87 Crane JD, Palanivel R, Mottillo EP, Bujak AL, Wang H, Ford RJ et al. Inhibiting peripheral serotonin synthesis reduces obesity and metabolic dysfunction by promoting brown adipose tissue thermogenesis. Nat Med 2015; 21: 166-172.

88 Zhang Q, Zhu Y, Zhou W, Gao L, Yuan L, Han X. Serotonin receptor 2 C and insulin secretion. PloS One 2013; 8: e54250.

89 Simpson EH, Kellendonk C, Ward RD, Richards V, Lipatova O, Fairhurst S et al. Pharmacologic rescue of motivational deficit in an animal model of the negative symptoms of schizophrenia. Biol Psychiatry 2011; 69: 928-935.

90 Kazdin AE, Rabbit SM. Novel models for delivering mental health services and reducing the burdens of mental illness. Clin Psychol Sci 2013; 1: 20.

91 Gragnoli C. PSMD9 gene in the NIDDM2 locus is linked to type 2 diabetes in Italians. J Cell Physiol 2010; 222: 265-267.

92 Lee YH, Kim JH, Song GG. Pathway analysis of a genome-wide association study in schizophrenia. Gene 2013; 525: 107-115.

93 Sangith N, Srinivasaraghavan K, Sahu I, Desai A, Medipally S, Somavarappu AK et al. Discovery of novel interacting partners of PSMD9, a proteasomal chaperone: role of an atypical and versatile PDZ-domain motif interaction and identification of putative functional modules. FEBS Open Bio 2014; 4: 571-583.

94 Nomiyama T, Tanaka Y, Piao L, Nagasaka K, Sakai K, Ogihara T et al. The polymorphism of manganese superoxide dismutase is associated with diabetic 
nephropathy in Japanese type 2 diabetic patients. J Hum Genet 2003; 48: 138-141.

95 Vats $\mathrm{P}$, Sagar N, Singh TP, Banerjee M. Association of superoxide dismutases (SOD1 and SOD2) and glutathione peroxidase 1 (GPx1) gene polymorphisms with type 2 diabetes mellitus. Free Radic Res 2015; 49: 17-24.

96 Zai CC, Tiwari AK, Basile V, de Luca V, Muller DJ, Voineskos AN et al. Oxidative stress in tardive dyskinesia: genetic association study and meta-analysis of NADPH quinine oxidoreductase 1 (NQO1) and Superoxide dismutase 2 (SOD2, MnSOD) genes. Prog Neuropsychopharmacol Biol Psychiatry 2010; 34: 50-56.

97 Bid HK, Konwar R, Saxena M, Chaudhari P, Agrawal CG, Banerjee M. Association of glutathione S-transferase (GSTM1, T1 and P1) gene polymorphisms with type 2 diabetes mellitus in north Indian population. J Postgrad Med 2010; 56: 176-181.

98 Pae CU, Yu HS, Kim JJ, Kim W, Lee CU, Lee SJ et al. Glutathione S-transferase M1 polymorphism may contribute to schizophrenia in the Korean population. Psychiatr Genet 2004; 14: 147-150.

99 Baker WA, Hitman GA, Hawrami K, McCarthy MI, Riikonen A, Tuomilehto-Wolf E et al. Apolipoprotein $D$ gene polymorphism: a new genetic marker for type 2 diabetic subjects in Nauru and south India. Diabet Med 1994; 11: 947-952.

100 Zhang X, Li D, Duan S, Duan Y, Chen Q, Li X et al. Analysis of the association between apolipoprotein $D$ and schizophrenia. Neuropsychobiology 2006; 54: 40-44.

101 Sandhu MS, Weedon MN, Fawcett KA, Wasson J, Debenham SL, Daly A et al. Common variants in WFS1 confer risk of type 2 diabetes. Nat Genet 2007; 39: 951-953.

102 Martorell L, Zaera MG, Valero J, Serrano D, Figuera L, Joven J et al. The WFS1 (Wolfram syndrome 1) is not a major susceptibility gene for the development of psychiatric disorders. Psychiatr Genet 2003; 13: 29-32.

103 Torres R, Leroy E, Hu X, Katrivanou A, Gourzis P, Papachatzopoulou A et al. Mutation screening of the Wolfram syndrome gene in psychiatric patients. Mol Psychiatry 2001; 6: 39-43.

104 Futamura T, Toyooka K, Iritani S, Niizato K, Nakamura R, Tsuchiya K et al. Abnormal expression of epidermal growth factor and its receptor in the forebrain and serum of schizophrenic patients. Mol Psychiatry 2002; 7: 673-682.

105 Al-Salam S, Hameed R, Parvez H, Adeghate E. Pattern of distribution of IGF-1 and EGF in pancreatic islets of type 2 diabetic patients. Islets 2009; 1: 102-105.

106 Anttila S, Illi A, Kampman O, Mattila KM, Lehtimaki T, Leinonen E. Association of EGF polymorphism with schizophrenia in Finnish men. Neuroreport 2004; 15: 1215-1218.

107 Watanabe Y, Fukui N, Muratake T, Kaneko N, Someya T. No association of EGF polymorphism with schizophrenia in a Japanese population. Neuroreport 2005; 16: 403-405.

108 Boraska V, Rayner NW, Groves CJ, Frayling TM, Diakite M, Rockett KA et al. Largescale association analysis of TNF/LTA gene region polymorphisms in type 2 diabetes. BMC Med Genet 2010; 11: 69.

109 Rasmussen SK, Urhammer SA, Jensen JN, Hansen T, Borch-Johnsen K, Pedersen O. The -238 and $-308 \mathrm{G}-->$ A polymorphisms of the tumor necrosis factor alpha gene promoter are not associated with features of the insulin resistance syndrome or altered birth weight in Danish Caucasians. J Clin Endocrinol Metab 2000; 85: 1731-1734.

110 Naz M, Riaz M, Saleem M. Potential role of neuregulin 1 and TNF-alpha (-308) polymorphism in schizophrenia patients visiting hospitals in Lahore, Pakistan. Mol Biol Rep 2011; 38: 4709-4714.

111 Chauhan G, Kaur I, Tabassum R, Dwivedi OP, Ghosh S, Tandon N et al. Common variants of homocysteine metabolism pathway genes and risk of type 2 diabetes and related traits in Indians. Exp Diabetes Res 2012; 2012: 960318.

112 Mabrouk H, Douki W, Mechri A, Younes MK, Omezzine A, Bouslama A et al. [Hyperhomocysteinemia and schizophrenia: case control study]. L'Encephale 2011; 37: 308-313.

113 Alkelai A, Greenbaum L, Lupoli S, Kohn Y, Sarner-Kanyas K, Ben-Asher E et al. Association of the type 2 diabetes mellitus susceptibility gene, TCF7L2, with schizophrenia in an Arab-Israeli family sample. PloS One 2012; 7: e29228.

114 Hansen T, Ingason A, Djurovic S, Melle I, Fenger M, Gustafsson O et al. At-risk variant in TCF7L2 for type II diabetes increases risk of schizophrenia. Biol Psychiatry 2011; 70: 59-63.

115 Kajio Y, Kondo K, Saito T, Iwayama Y, Aleksic B, Yamada K et al. Genetic association study between the detected risk variants based upon type II diabetes GWAS and psychotic disorders in the Japanese population. J Hum Genet 2014; 59: 54-56.

116 Tsai SJ, Hong CJ, Liao DL, Chiang CH. Distribution of androgen receptor CAG repeat polymorphism in Chinese schizophrenia and its correlation with age at onset. Psychoneuroendocrinology 2006; 31: 270-274.
117 Arranz M, Sharma T, Sham P, Kerwin R, Nanko S, Owen M et al. Schizophrenia and the androgen receptor gene: report of a sibship showing co-segregation with Reifenstein syndrome but no evidence for linkage in 23 multiply affected families. Am J Med Genet 1995; 60: 377-381.

118 Crow TJ, Poulter M, Lofthouse R, Chen G, Shah T, Bass N et al. Male siblings with schizophrenia share alleles at the androgen receptor above chance expectation. Am J Med Genet 1993; 48: 159-160.

119 Stanworth RD, Kapoor D, Channer KS, Jones TH. Androgen receptor CAG repeat polymorphism is associated with serum testosterone levels, obesity and serum leptin in men with type 2 diabetes. Eur J Endocrinol 2008; 159: 739-746.

120 Sahin M, Delibasi T. Possible effects of androgens on islet cell functions. Med Hypotheses 2009; 72: 711-712.

121 Nordman S, Ding B, Ostenson CG, Karvestedt L, Brismar K, Efendic S et al. Leu7Pro polymorphism in the neuropeptide $Y$ (NPY) gene is associated with impaired glucose tolerance and type 2 diabetes in Swedish men. Exp Clin Endocrinol Diabetes 2005; 113: 282-287.

122 Itokawa M, Arai M, Kato S, Ogata Y, Furukawa A, Haga S et al. Association between a novel polymorphism in the promoter region of the neuropeptide $Y$ gene and schizophrenia in humans. Neurosci Lett 2003; 347: 202-204.

123 Inoue Y, Shinkai T, Utsunomiya K, Sakata S, Fukunaka Y, Yamaguchi W et al. No association between a functional polymorphism in the promoter region of the neuropeptide $\mathrm{Y}$ gene $(-485 \mathrm{C}>\mathrm{T})$ and schizophrenia. Neurosci Lett 2009; 452: 72-74.

124 Wang J, Ciofi P, Crowley WR. Neuropeptide Y suppresses prolactin secretion from rat anterior pituitary cells: evidence for interactions with dopamine through inhibitory coupling to calcium entry. Endocrinology 1996; 137: 587-594.

125 Vaag AA, Grunnet LG, Arora GP, Brons C. The thrifty phenotype hypothesis revisited. Diabetologia 2012; 55: 2085-2088.

126 Nohesara S, Ghadirivasfi M, Mostafavi S, Eskandari MR, Ahmadkhaniha H, Thiagalingam $\mathrm{S}$ et al. DNA hypomethylation of MB-COMT promoter in the DNA derived from saliva in schizophrenia and bipolar disorder. J Psychiatry Res 2011; 45: $1432-1438$.

127 Hales CN, Barker DJ. The thrifty phenotype hypothesis. Br Med Bull 2001; 60: 5-20.

128 Gragnoli C, Stanojevic V, Gorini A, Von Preussenthal GM, Thomas MK, Habener JF. IPF-1/MODY4 gene missense mutation in an Italian family with type 2 and gestational diabetes. Metabolism 2005; 54: 983-988.

129 Park JH, Stoffers DA, Nicholls RD, Simmons RA. Development of type 2 diabetes following intrauterine growth retardation in rats is associated with progressive epigenetic silencing of Pdx1. J Clin Invest 2008; 118: 2316-2324.

130 Byars SG, Stearns SC, Boomsma JJ. Opposite risk patterns for autism and schizophrenia are associated with normal variation in birth size: phenotypic support for hypothesized diametric gene-dosage effects. Proc Biol Sci 2014; 281: 20140604.

131 deMoura EG, Passos MC. Neonatal programming of body weight regulation and energetic metabolism. Biosci Rep 2005; 25: 251-269.

132 Shorter KR, Miller BH. Epigenetic mechanisms in schizophrenia. Prog Biophys Mol Biol 2015; 118: 1-7.

133 Dai D, Cheng J, Zhou K, Lv Y, Zhuang Q, Zheng R et al. Significant association between DRD3 gene body methylation and schizophrenia. Psychiatry Res 2014; 220: 772-777.

134 Petronis A, Gottesman II, Kan P, Kennedy JL, Basile VS, Paterson AD et al. Monozygotic twins exhibit numerous epigenetic differences: clues to twin discordance? Schizophr Bull 2003; 29: 169-178.

135 Abdolmaleky HM, Nohesara S, Ghadirivasfi M, Lambert AW, Ahmadkhaniha H, Ozturk $S$ et al. DNA hypermethylation of serotonin transporter gene promoter in drug naive patients with schizophrenia. Schizophr Res 2014; 152: 373-380.

136 Abdolmaleky HM, Smith CL, Zhou JR, Thiagalingam S. Epigenetic alterations of the dopaminergic system in major psychiatric disorders. Methods Mol Biol 2008; 448: $187-212$.

137 Melas PA, Rogdaki M, Osby U, Schalling M, Lavebratt C, Ekstrom TJ. Epigenetic aberrations in leukocytes of patients with schizophrenia: association of global DNA methylation with antipsychotic drug treatment and disease onset. FASEB J 2012; 26: 2712-2718.

This work is licensed under a Creative Commons Attribution 4.0 International License. The images or other third party material in this article are included in the article's Creative Commons license, unless indicated
otherwise in the credit line; if the material is not included under the Creative Commons license, users will need to obtain permission from the license holder to reproduce the material. To view a copy of this license, visit http://creativecommons.org/licenses/ by/4.0/ 